\title{
A Multistage Regulation Method for the Pad and Fan Cooling System
}

\author{
Guofeng Han ${ }^{1,2}$, Xiaolong Feng ${ }^{1,3}$, Shumei Zhao ${ }^{1, \text { * }}$ \\ ${ }^{1}$ Key Laboratory of Agricultural Engineering in Structure and Environment, Ministry of Agriculture, College of Water Resources and Civil \\ Engineering, China Agricultural University, Beijing, China \\ ${ }^{2}$ Faculty of Agriculture, Kyushu University, Fukuoka, Japan \\ ${ }^{3}$ Qingdao Bigherdsman Machinery Co., Ltd., Qingdao, China
}

Email address:

hangf07@126.com (Guofeng Han), long18356070576@163.com (Xiaolong Feng), zhaoshum@cau.edu.cn (Shumei Zhao)

${ }^{*}$ Corresponding author

\section{To cite this article:}

Guofeng Han, Xiaolong Feng, Shumei Zhao. A Multistage Regulation Method for the Pad and Fan Cooling System. Agriculture, Forestry and Fisheries. Vol. 7, No. 1, 2018, pp. 1-5. doi: 10.11648/j.aff.20180701.11

Received: November 17, 2017; Accepted: November 28, 2017; Published: December 20, 2017

\begin{abstract}
The aim of this study was to investigate the abrupt temperature drop problem and its countermeasures of pad and fan cooling system in confined poultry house in summer. The extent and distribution of abrupt temperature drop in a commercial laying-hen house in north China were investigated through field tests. The results showed that over half of poultry house was cooled by more than $5^{\circ} \mathrm{C}$ (maximum reached $12.4^{\circ} \mathrm{C}$ ) within 25 min after starting the evaporative cooling system under traditional ON/OFF mode. This mode might cause negative effects on layers. In order to attenuate this problem, a multistage regulation method of evaporative cooling system was developed. The water supply pipe was transformed by adding a specially designed water repartition plate to the original water supply system. The water repartition plate can control the watered area of pad. Then four degrees of watered area could be achieved as $1 / 8,1 / 4,1 / 2$, and the full of pad area, and then gradual cooling process has been achieved. The target temperature was reached gradually through modifying the start temperature and single-cooling range, then a relative long period for chickens to adopt cooling process has been realized. This regulation method has been tested in laboratory. The results showed that gradually watering and cooling works well under multistage regulation. The cooling efficiencies from $1^{\text {st }}$ to $4^{\text {th }}$ stage were $15.84 \%, 30.53 \%, 56.67 \%$ and $83.70 \%$, respectively, which matched well with prediction. In conclusion, the multistage regulation method was able to, as a new solution, alleviate the problem caused by traditional ON/OFF mode of evaporative cooling system in confined poultry house.
\end{abstract}

Keywords: Poultry House, Evaporative Cooling System, Abrupt Temperature Drop, Multi-Stages Regulation, Chickens

\section{Introduction}

Indoor environment, especially temperature, is essential for the production performance of layers [1]. Therefore, the environmental control of the poultry house has become an important part of the large scale farming [2]. The environmental control mainly targets control of the indoor air temperature, relative humidity, airflow, concentrations of harmful gases, and the other environmental factors. Air temperature is an important parameter for the layer house environment regulation. In large scale layer poultry houses, heat dissipation of chicken has a significant impact on the air temperature in a poultry house [3]. In summer, the heat dissipation is a kind of environmental heat load. The high temperature causes the heat stress on the chicken. Heat stress could also affect laying hens' breathing and blood circulation system. When the room temperature exceeds $30^{\circ} \mathrm{C}$, laying hens will have hot breath, a significant rise in the $\mathrm{CO}_{2}$ concentration in the body, leading to respiratory alkalosis [4]. In addition, heat stress certainly also affects the immune function of laying hen [5]. Constant heat stress causes a decrease of the egg production rate of laying hens, as well as negative effects on egg quality [6]. From the perspective of laying hens' energy consumption, the feed intake of laying hens decreases sharply when the indoor air temperature is over $28^{\circ} \mathrm{C}$. The available energy for production declines when the 
temperature is more than $33^{\circ} \mathrm{C}$. When the ambient temperature was within the range of $25 \sim 30^{\circ} \mathrm{C}$, the laying rate and egg weight declined $1.5 \%$ and $0.3 \mathrm{~g}$ respectively for $1^{\circ} \mathrm{C}$ increase in the environment temperature [7]. At the same time, cold stress is also a common stress for poultry. As the increase of the duration of cold stress, the impact on lymphocyte proliferation in vitro response delay is more and more serious [8]. It is generally believed that the laying rate and food conversion ratio are affected when environment temperature was below $7^{\circ} \mathrm{C}$ or above $29^{\circ} \mathrm{C}$. So excessive cold stress and heat stress problems should be focused and avoided in confined poultry house [9].

The pad and fan cooling system was developed as early as the 1950's in the US. It is widely applied in poultry houses for excellent cooling effect and low cost [10]. Many field tests about evaporative cooling system showed that the system has a significant effect in confined poultry house in summer [11]. It can effectively solve the problem of heat stress and improve the production performance of hens in summer [12]. It was also reported that multistage regulation can control the cooling range of wet pad and fan cooling system [13].

The magnitude and distribution of abrupt temperature drop in a typical commercial laying-hen house in north China were investigated through field tests. In order to solve this problem, a multistage regulation method of pad and fan cooling system was proposed. The water supply pipe was transformed by adding a special designed water repartition plate on the original water supply system. This method is able to provide a technical solution to eliminate the abrupt temperature drop caused by the traditional regulation mode of pad and fan cooling system in confined poultry house.

\section{Materials and Methods}

\subsection{Experimental Poultry House}

The poultry house was located in Shijiazhuang city, Hebei province. It was a confined poultry house (width, $11 \mathrm{~m}$; length, $76 \mathrm{~m}$; height, $3.75 \mathrm{~m}$ ). The poultry house included along 8,000 birds with stepwise cages. The poultry house was applied with mechanical ventilation and evaporative cooling system for room temperature management in summer. Both the south and north walls had 28 air inlets (width, $0.27 \mathrm{~m}$; length, $0.7 \mathrm{~m}$ ). The east gable wall was inserted with 6 axial flow fans. The wet pads were installed in the west gable wall as well as south and north walls, the wet pads in each wall were divided into two sections (4.5 m long; $1.9 \mathrm{~m}$ wide).

\subsection{Temperature Measurement}

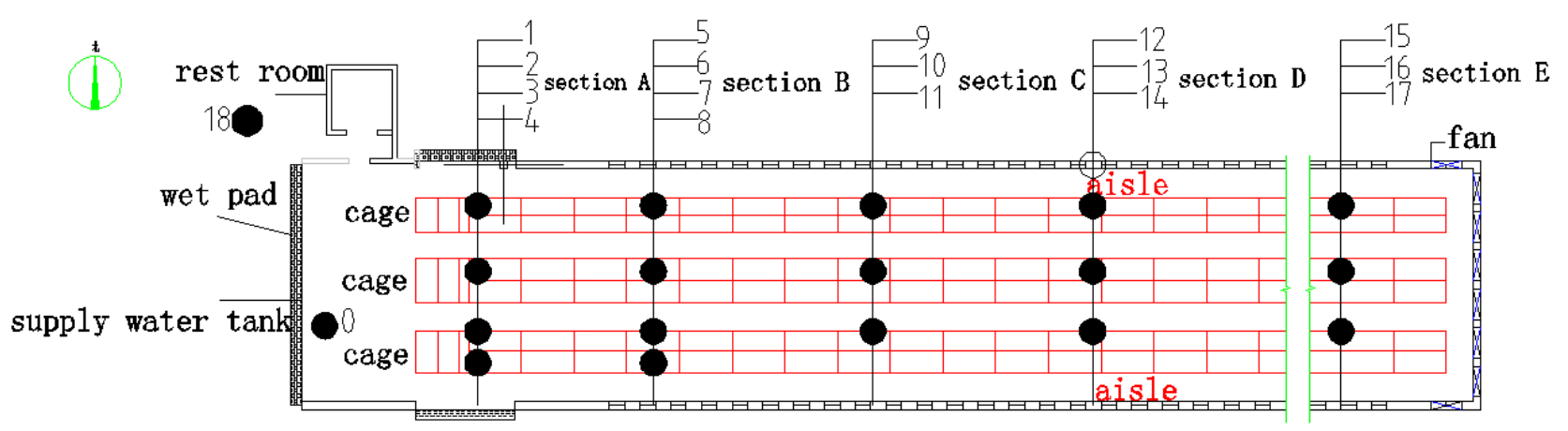

Figure 1. Floor plan of test points in poultry house.

The air temperatures (inside and outside of poultry house) were measured by small size sensors for temperature and humidity (Thermo Recorder RS-13, Japan). All sensors were connected to the data loggers, then data was recorded every 5 min. All the devices were calibrated before the field test experiment. Air temperature data was collected at 18 measuring points near the birds at a $0.85 \mathrm{~m}$ height in the poultry house (Figure 1). One of the measuring points inside was near the wet pad with $2 \mathrm{~m}$ distance. The measuring points were set on $\mathrm{A} \sim \mathrm{E}$ sections in the feeding zone. $\mathrm{A} \sim \mathrm{E}$ sections were $8 \mathrm{~m}, 16 \mathrm{~m}, 26 \mathrm{~m}, 36 \mathrm{~m}$ and $70 \mathrm{~m}$ from the wet pad, respectively. At the same time, there was one temperature measuring point outside the poultry house. This point was set $2 \mathrm{~m}$ from the west gable wall with $1.8 \mathrm{~m}$ height.

\subsection{Improvement of the Multistage Regulation Method}

This method aimed to solve abrupt drop of air temperature under the traditional ON/OFF regulation mode. The problem was expected to be resolved through controlling the wet area of pad and develop the related devices without extra water supply system.

The wet pad water supply system mainly includes pump, pad, water supply tube, supply water tank, and return water tank, etc. The water supply pipe was transformed by adding a special designed water repartition plate on the original water supply system. The water repartition plate can control watered area of pad. The water plate has holes with different size. The size and distribution of holes were designed according to the actual water supply pipe and the expected multistage regulation. The spewed out water from water spray system could be stopped by the water plate when water supply pipe blowhole was covered with water plate hole. Then the pad cannot be watered (Figure 2). 


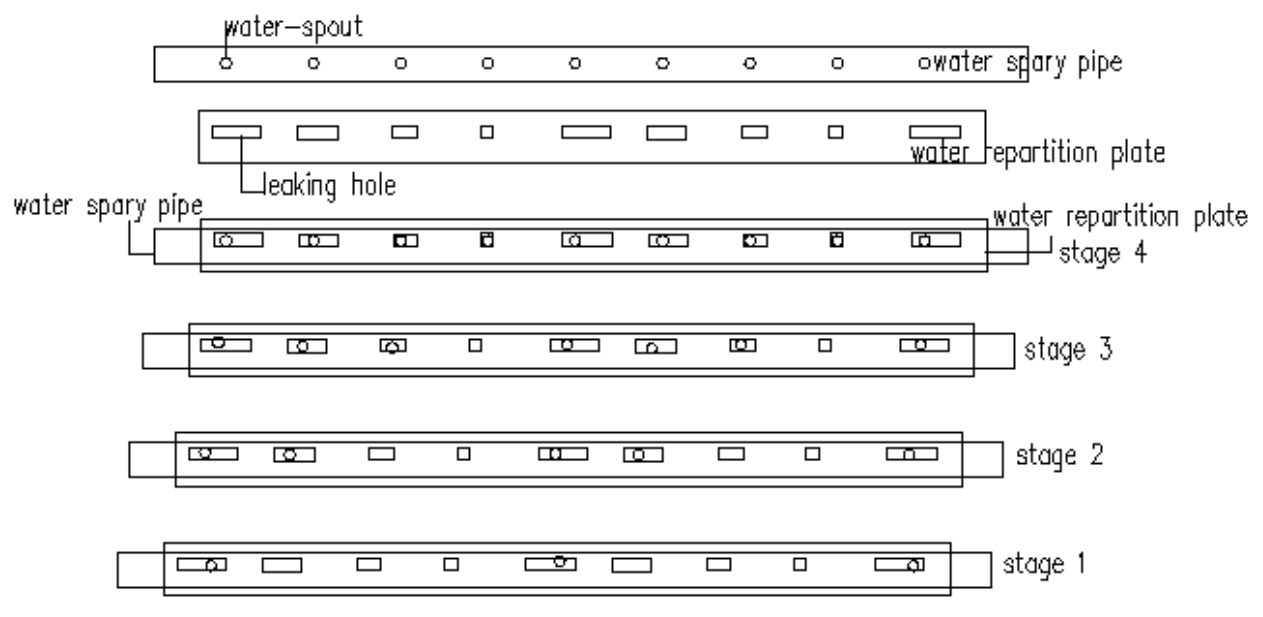

Figure 2. Water diversion board and spray pipe.

The distance between water spouts (holes in the pipe) was decided as $100 \mathrm{~mm}$ based on some spaying tests. The cooling effect was investigated by laboratory test using the multistage regulation system. The actual cooling efficiency was calculated according to the experimental results. In detail, a wind tunnel was used to provide a steady airflow. An experimental pad $(1600 \times 1500 \times 150 \mathrm{~mm})$ was used in the test. The dry bulb air temperature $\left(\mathrm{T}_{\mathrm{d}}\right)$ before and after the cooling was collected for cooling efficiency calculation. Temperature distribution after cooling pad was collected by thermocouples and a data acquisition unit (CADAC31, Japan). The air temperature was measured at 18 points in two sections, which were $300 \mathrm{~mm}$ and $1500 \mathrm{~mm}$ from the wet pad (Figure 3), respectively.

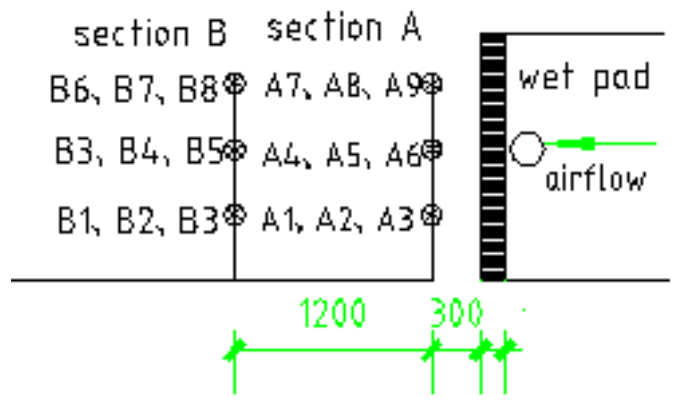

Figure 3. Measurement points distribution ( $\mathrm{mm})$.

\section{Results and Discussions}

\subsection{Air Temperature Distribution}

Table 1. Highest temperature of inside and outside during 5-15 June 2012.

\begin{tabular}{|c|c|c|c|c|c|c|c|c|c|c|c|}
\hline Date & $5 / 6$ & $6 / 6$ & $7 / 6$ & $8 / 6$ & $9 / 6$ & $10 / 6$ & $11 / 6$ & $12 / 6$ & $13 / 6$ & $14 / 6$ & $15 / 6$ \\
\hline Inside $\left({ }^{\circ} \mathrm{C}\right)$ & 33.2 & 33.2 & 31.8 & 33.4 & 35.2 & 30.4 & 32.9 & 31.9 & 31.2 & 31.5 & 32.6 \\
\hline Outside $\left({ }^{\circ} \mathrm{C}\right)$ & 34.8 & 34.5 & 33.6 & 36.3 & 39.2 & 33.3 & 36.8 & 37.6 & 32 & 32 & 34.1 \\
\hline
\end{tabular}

Table 2. Working time of the evaporative cooling system during Jun. 5-12 and Jun. 14-15, 2012.

\begin{tabular}{|c|c|c|c|c|c|c|c|c|c|c|}
\hline Date & $5 / 6$ & $6 / 6$ & $7 / 6$ & $8 / 6$ & $9 / 6$ & $10 / 6$ & $11 / 6$ & $12 / 6$ & $14 / 6$ & $15 / 6$ \\
\hline Start time & $14: 30$ & $14: 55$ & $13: 45$ & $14: 30$ & $12: 30$ & $15: 00$ & $12: 20$ & $11: 20$ & $14: 15$ & $14: 10$ \\
\hline End time & $17: 30$ & $17: 45$ & $16: 00$ & $17: 30$ & $16: 00$ & $17: 00$ & $16: 40$ & $17: 00$ & $16: 50$ & $17: 50$ \\
\hline
\end{tabular}

The pad and fan cooling system was applied from June 5-12, and June 14-15, 2012 for a total of 10 days. The daily highest temperature of inside and outside of poultry house was shown in Table 1 and working period of the evaporative cooling system was shown in Table 2. The maximum declines of room temperature within 25 min after evaporative cooling system operation were regarded as the range of the temperature drop. Table 3 showed the air temperature distribution after evaporative cooling system operation, the values were averages of few air temperature declines in different sections as described in Figure 1 in the poultry house.

Table 3 included the cooling effect observed within $25 \mathrm{~min}$ after starting the cooling system, which indicated that over half of the poultry house was cooled by more than $5^{\circ} \mathrm{C}$ within 25 min after starting the evaporative cooling system. The cooling effect increased with decreasing the distance to the wet pad. It agreed with pervious study that cooling effect of evaporative cooling system was affected by the distance to wet pad [14], as the cooled air was warmed by the heat production of animals or mixed with outside warm air. In this study, the cooling range was from $8^{\circ} \mathrm{C}$ to $10^{\circ} \mathrm{C}$ (the maximum reached $10.1^{\circ} \mathrm{C}$ ) at section $\mathrm{A}$ and from $5^{\circ} \mathrm{C}$ to $7^{\circ} \mathrm{C}$ (the maximum reached $7.1^{\circ} \mathrm{C}$ ) at section $\mathrm{D}$. 
Table 3. The distribution of average air temperature $\left({ }^{\circ} \mathrm{C}\right)$ in poultry house.

\begin{tabular}{|c|c|c|c|c|c|c|c|c|}
\hline \multirow{2}{*}{ Measurement section } & \multicolumn{8}{|c|}{ Date } \\
\hline & 6.5 & 6.6 & 6.7 & 6.8 & 6.9 & 6.10 & 6.11 & 6.12 \\
\hline 0 point & 10.1 & 12.8 & 7.6 & 11.4 & 12.4 & 10.7 & 12.3 & 12.7 \\
\hline Section A & 7.6 & 9.7 & 7.6 & 8.4 & 9.7 & 9.4 & 10.1 & 10.0 \\
\hline Section B & 6.4 & 8.4 & 6.2 & 6.7 & 7.8 & 7.5 & 8.8 & 7.5 \\
\hline Section C & 6.2 & 7.7 & 5.9 & 6.8 & 7.9 & 7.0 & 8.1 & 6.2 \\
\hline Section D & 5.5 & 7.1 & 5.3 & 5.8 & 6.5 & 5.8 & 6.7 & 5.1 \\
\hline Section E & 3.7 & 4.7 & 3.8 & 3.5 & 3.6 & 3.6 & 3.9 & 3.1 \\
\hline
\end{tabular}

Note: The average temperature-fall range of test points is the average difference value of maximum and minimum temperature within 25 min after evaporative cooling system working on the same day.

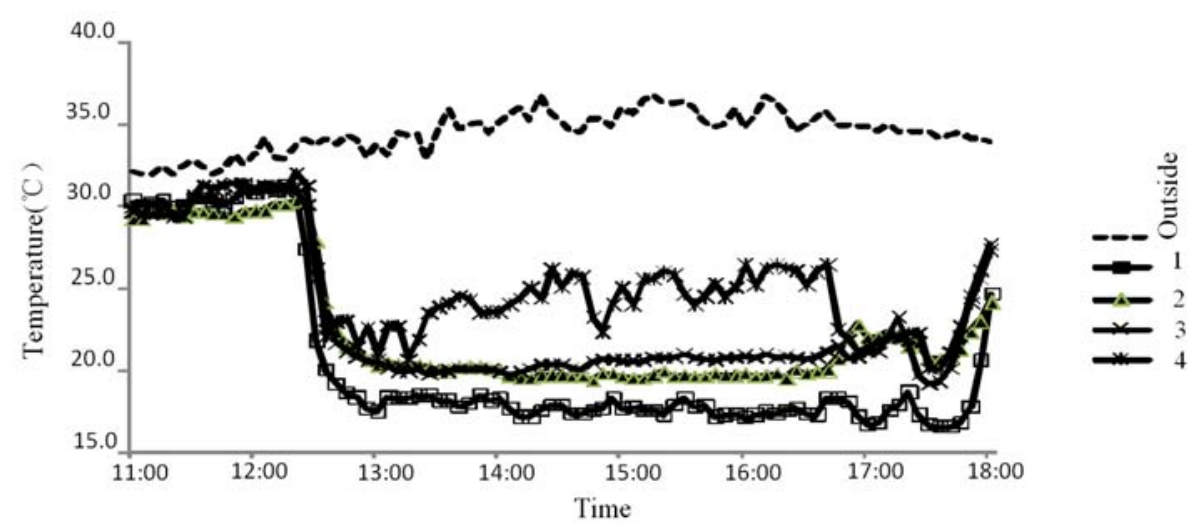

Figure 4. Temperature changes of outside and cross section $A$ ( $8 \mathrm{~m}$ from wet pad).

In order to understand the extent and characteristics of the abrupt temperature falling, the temperature changes at section A was individually shown in Figure 4 . The temperature changes at point 4 were different to that in other sections, which might be affected by the nearest pad condition or disturbed airflow. The temperature changes in other three points (point 1, 2 and 3) showed similar pattern and good cooling performance. The temperature falling in point 1 to 4 within $25 \mathrm{~min}$ after starting the evaporative cooling system was $11.8^{\circ} \mathrm{C}, 8.7^{\circ} \mathrm{C}, 9.4^{\circ} \mathrm{C}$ and $9.9^{\circ} \mathrm{C}$, respectively. A dramatic decreasing of environment temperature in short term might be a stress for poultry, which has potential to cause negative effects for poultry health [15], like increasing the pathogenesis of necrotic enteritis [16]. It could be concluded that the abrupt temperature drop caused by traditional regulation mode of evaporative cooling system might be a serious problem in summer.

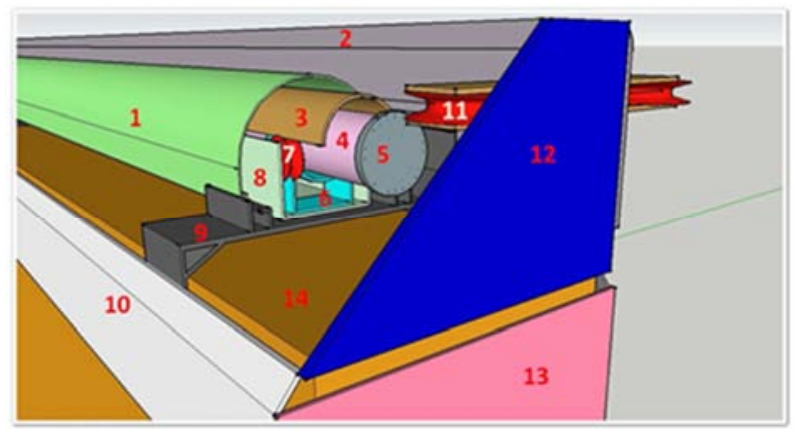

Figure 5. Schematic of water supply system for wet-pad and fan cooling: 1, back water plate; 2 , framework; 3, water plate; 4, spray pipe; 5, pipe plug; 6 , pipe carrier; 7 , small pulley; 8 , water chute; 9, plate; 10, front plate; 11 , guide pulley; 12, cover; 13, side plate; 14, wet pad.

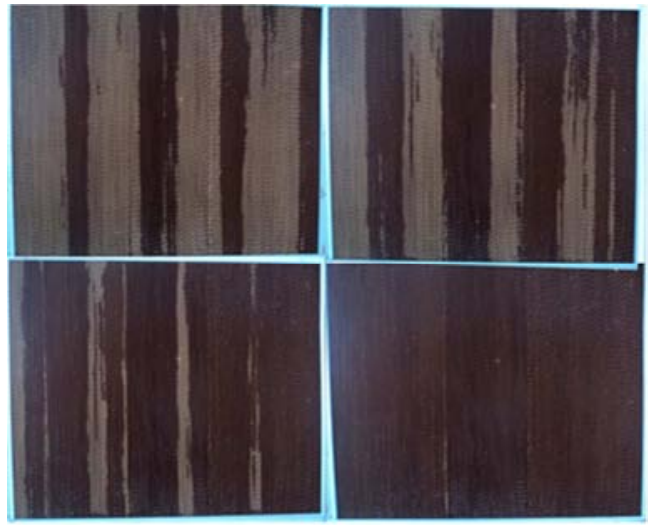

Figure 6. Watered area of cooling pad.

\subsection{Transformation of the Water Supply System}

The water supply system was transformed base on the original wet pad. Some new parts were added. For example, water plate, water chute, guide pulley and small pulley (Figure 5). When the multistage regulation system works, the wet pad opens the different cooling level based on the target temperature. With water plate moving along the axial displacement, wet area could be divided into four grades. The water plate can control watered area of pad. So four degrees of watered area can be achieved as 1/8, 1/4, 1/2, and the full of pad area, and then gradual cooling could be achieved.

\subsection{The Cooling Effect of Multistage Regulation}

Figure 6 showed that the actual operation effect under the different multi-stage regulations. The results showed that the temperature was uneven at section $\mathrm{A}$, but the temperature 
distribution was uniform at section B (Figure 3; data not shown). The results showed that the distance for hot and cold air well mixed under multi-stage regulation at a distance more than $0.3 \mathrm{~m}$, but less than $1.5 \mathrm{~m}$. The cooling efficiency under the multi-stage regulation was calculated and shown in Table 4 by temperature data in section B (Figure 3).

Table 4. Cooling results of multi-stage regulation.

\begin{tabular}{lllll}
\hline & \multicolumn{4}{l}{ Cooling stages } \\
\cline { 2 - 5 } & $\mathbf{S - 1}$ & $\mathbf{S - 2}$ & $\mathbf{S - 3}$ & $\mathbf{S - 4}$ \\
\hline $\mathrm{T}_{\mathrm{d}}$ before cooling & 20.4 & 20.2 & 20.0 & 20.0 \\
$\mathrm{~T}_{\mathrm{w}}$ before cooling & 11.2 & 12.0 & 12.6 & 14.0 \\
$\mathrm{~T}_{\mathrm{d}}$ after cooling & 18.9 & 17.7 & 15.8 & 15.0 \\
Cooling efficiency & 15.84 & 30.53 & 56.67 & 83.70 \\
\hline
\end{tabular}

$\mathrm{T}_{\mathrm{d}}$, dry bulb temperature; $\mathrm{T}_{\mathrm{w}}$, wet bulb temperature; $\mathrm{S}-$, cooling stage.

The actual cooling effect worked well as predicted, and the cooling efficiency was only $15.8 \%$ under stage 1 , as well as, from stage $2^{\text {nd }}$ to stage $4^{\text {th }}$ were $30.5 \%, 56.7 \%$ and $83.7 \%$ cooling efficiency, respectively. As predicted about the cooling process, the cooling efficiency of the multi-stage regulation increased with watered area augment. The tests indicated that the pad cooling system could achieve different cooling efficiencies under modified regulation mode. With the multi-stages regulation mode and devices, the cooling capacity and speed of the evaporative cooling system could be controlled.

\section{Conclusion}

The pad and fan cooling system has a significant cooling effect in the confined poultry house in summer in north China. However, the dramatic temperature drop in a short term might be a serious problem for poultry health. The results of field tests showed that over half of the layer house could be cooled for $5^{\circ} \mathrm{C}$ within $25 \mathrm{~min}$ of cooling system operation. The maximum cooling effect reached $12.7^{\circ} \mathrm{C}$ in the area near wet pad in poultry house.

The multi-stages regulation mode of evaporative cooling system could be realized by controlling watered area of the pad without adding extra water supply system. The devices applied for multi-stage regulation had been developed. The results of simulation tests in laboratory showed that under the multi-stages regulation mode, the cooling process of evaporative cooling system could be controlled, and the problem of dramatic temperature falling in short term could be relieved.

Due to the complexity of the production field and the lack of experimental conditions, the multistage regulation method and equipment have not been applied to production. Field tests for this new regulation method are needed in future research.

\section{Acknowledgements}

This work was supported by the China Agricultural Research Systems (CARS-40-K19).

\section{References}

[1] P. Y. Hester, "Preventive Measures for Avoiding the Deleterious Effects of Heat Stress on Egg Production and Quality," Egg Innovations and Strategies for Improvements. 2017, 337-346.

[2] H. Xin, R. S. Gates, A. R. Green, F. M. Mitloehner, P. A. Moore $\mathrm{Jr}$, and C. M. Wathes, "Environmental impacts and sustainability of egg production systems," Poult. Sci. 2011, 90 (1), 263-277.

[3] A. Aggarwal, and R. Upadhyay, "Heat Stress and Animal Productivity,” Springer, India, 2012, pp: 1-20.

[4] Q. Wu, H. Lin, and Q. Yang, "The study for temperature and diet nutrition level on the effects of the quality of laying hens," J. Shandong Agr. Univ. 1990, 2 (23): 18-19. http://www.cqvip.com/QK/90916X/.

[5] M. S. Monson, A. G. Van Goor, C. M. Ashwell, M. E. Persia, M F. Rothschild, C. J. Schmidt, and S. J. Lamont, "Exposure to Heat Stress and an Immune Stimulus Affects Gene Expression in Chicken Immune Tissues," Animal Industry Report, 2017, 663 (1): 47.

[6] A. M. Fouad, W. Chen, D. Ruan, S. Wang, W. G. Xia, and C. T. Zheng, "Impact of heat stress on meat, egg quality, immunity and fertility in poultry and nutritional factors that overcome these effects: A review,” Int. J. Poult. Sci. 2016, 15 (3), 81- 95.

[7] Y. You, "Research on the Effects of Henhouse Environment Control on Production Performance," Ph. D Thesis, College of Engineering, China Agr. Univ. 2005, Beijing, China.

[8] V. E. Beattiea, N. E. O'connell, and W. Moss, "Influence of environmental enrichment on the behavior, performance and meat quality of domestic pigs," Livest. Prod. Sci. 2000, 65 (1): 71-79.

[9] S. Xuan, X. Wang, and Q. Shao, "Thermal stress layer chicken diet control measures," J. Zhejiang Anim. Vet. 2003, 5: 14-15.

[10] L. Steve, "Poultry heat stress," Chinese Poult. 2002, 24:34-37. http://www.zgjq.cn/eqydk/.

[11] B. N. Hangalapura, M. G. B. Nieuwland, G. de Vries Reilingh, H. V. D. Brand, B. Kemp, and H. K. Parmentier, "Durations of cold stress modulates overall immunity of chicken lines divergently selected for antibody responses," Poult. Sci. 2004, 83 (5): 765-775.

[12] Z. Wang, "The effects of light and temperature on the laying hen's rate," Breed. Technol. Consultant. 2005, 3-5. http://yangzhijishuguwen.zazhi.com.cn.

[13] E. Tan, "Study on Cooling Pad System Regulation of Confined Poultry House," MS Thesis, College of Engineering, China Agr. Univ. 2010, Beijing, China.

[14] J. Xu, Y. Li, R. Z. Wang, W. Liu, and P. Zhou, "Experimental performance of evaporative cooling pad systems in greenhouses in humid subtropical climates," Applied Energy, 2015, 138: 291-301.

[15] S. Tian, and S. Jin, "The influence of cold stress on animals and its prevention,” J. Hebei North Univ. (Nat. Sci. Ed.). 2005, 2: 55-57.

[16] V. Tsiouris, I. Georgopoulou, C. Batzios, N. Pappaioannou, R. Ducatelle, and P. Fortomaris, "The effect of cold stress on the pathogenesis of necrotic enteritis in broiler chicks," Avian Pathol. 2015, 44 (6): 430-435. 